\title{
METHODOLOGY FOR DETERMINING STANDARDS OF TECHNICAL OPERATION OF VEHICLES TAKING INTO ACCOUNT THEIR TECHNICAL CONDITION
}

\author{
Farit Khaliullin $^{1,2}$, Rishat Akhmetzyanov ${ }^{2}$, Fanis Arslanov ${ }^{3}$, Azamat Caview ${ }^{3}$ \\ ${ }^{1}$ Kazan National Research Technical University named after A. N. Tupolev, Russia; \\ ${ }^{2}$ Kazan State Agrarian University, Russia; ${ }^{3}$ Izhevsk State Agricultural Academy, Russia \\ khaliullin_kai_adis@mail.ru, rishat83@mail.ru,ffanis@mail.ru, aif143009@gmail.com
}

\begin{abstract}
One of the important standards of technical operation of motor vehicles is the frequency of their maintenance. The correct definition of it directly affects the amount of specific operating costs and is one of the most important tasks of engineering and technical workers. At the same time, their reduced values, although they lead to an increase in the reliability of vehicles, but they increase the frequency of downtime and the cost of operation, as well as increase the share of unused resources of serviced systems and mechanisms. In this paper, we consider an economic-probabilistic method for determining the frequency of maintenance. There are two tactics for implementing this method: by operating time and by technical condition. For all its simplicity, the method of determining the operating time has a number of disadvantages, namely, it does not take into account the technical condition of the serviced mechanisms and units at the current moment. This increases the complexity of performing maintenance operations, and their cost increases accordingly. The method of determining the frequency of maintenance by condition is considered. In this case, all work on the maintenance of mechanisms and aggregates of vehicles is divided into diagnostic and executive components. At the first stage, their technical condition and resource are determined until the next scheduled maintenance. If this resource is not enough to run before this event, then a decision is made to perform the executive part of the work. With a larger resource, the executive part is postponed until the next scheduled maintenance. The determination of the frequency of maintenance is based on the results of comparing the specific operating costs for routine repairs with the weighted average costs for maintenance and routine repairs.
\end{abstract}

Key words: technical operation standards, rejection, reliability, maintenance frequency.

\section{Introduction}

The frequency of car maintenance is one of the main standards of technical operation. The correct definition of it directly affects the amount of specific operating costs and is one of the most important tasks of engineering and technical workers. At the same time, their reduced values, although they lead to an increase in the reliability of vehicles, but increase the frequency of downtime and the cost of operation, as well as increase the share of unused resources of the serviced systems and mechanisms. There are different approaches to solving this problem. In [1], the authors propose a preliminary statistical analysis of the selected parameters of car maintenance in road transport companies. These results provide comparative material that is useful for evaluating the maintenance efficiency of various road transport systems. In [2], the authors analyze the reliability of transport, which is considered as a complex mechanical system in which all the elements of the system are connected in series, and each element includes parts connected in series. Failure of each part of the system will cause the entire vehicle to fail. Thus, the car is a system without redundancy. The methodology is illustrated by the presentation of the results of calculations of the intensity of maintenance and the cost of spare parts and car repairs. In [3], the author considers the optimal frequency of maintenance on the basis of multiple alternatives. The objective efficiency functions in this case are the damage and failure rates, which corresponds to the set of operational alternatives under consideration. This allows us to obtain the corresponding functions of subjective preferences, implying the proportionality of preferences to alternative damage and failure intensities. In the studies of the authors of the paper [4], regression analysis was used to analyze the correlation between the quality of service and customer loyalty in car service centres, and then the qualitative components of the modified Kano model were encoded to determine whether the statistical values correspond to the $F$-distribution. and were used to confirm the capabilities of the Kano model in quantitative studies. The author in the work [5] connects the parameters of vehicle maintenance and their efficiency not only with objective factors, but also with the operating conditions of vehicles.

Currently, methods of mathematical simulation of random processes $[1 ; 2]$ and analytical methods [3] are used to determine the frequency of maintenance of motor vehicles. Modeling methods allow us to take into account many technical and technological factors, although they are not without drawbacks due to the complexity of an adequate choice of accounting for the patterns of real processes of technical 
operation of cars. Let us consider a method for determining the periodicity of the technical condition of cars based on an array of data on the failure time.

\section{Status of the issue}

Let us consider the method of determining the technical condition of motor vehicles by the technical and economic method $[9 ; 10]$. As you know, the source data for this method is an array of data with dimension $\mathrm{N}$ by operating time $l_{i}(x)$ on refusal $n_{i}, i=1 \div N$. The characteristics of a random variable are determined from the selected array.

- probability of a random event:

$$
F(x)=P\left\{x_{i} \leq x\right\} \cong \frac{m(x)}{n},
$$

where $m(x)$ - number of random variables (failed vehicles) for the operating time of $x$.

- Refusal:

$$
F(x)=P\left\{x_{i} \leq x\right\} \cong \frac{m(x)}{n} .
$$

- Reliability:

$$
R(x)=P\left\{x_{i} \geq x\right\} \cong \frac{n-m(x)}{n} .
$$

Probability distribution density: $f(x)=F^{\prime}(x)$ insofar as

$$
F(x)=\frac{m(x)}{n},
$$

then at $n=$ const we get

$$
f(x)=\frac{1}{n} \frac{d m}{d x}
$$

- Gamma-percent resource $x_{j}$ :

$$
R(x)=P\left\{x_{i} \geq x\right\} \geq j
$$

According to these data, it is possible to determine the frequency of maintenance by methods based on the permissible level of reliability and on the regularity of changes in the technical condition parameter and its permissible value [11]. The first of them takes into account the technical condition of objects indirectly only through the coefficient of variation $\vartheta$ and the average value of the time-to-failure array $\bar{x}$. To apply the second method, it is necessary to have adequate information about the intensity of changes in the technical condition parameter by operating time.

Consider a method that uses the characteristics of an array of random values of time to failure, taking into account the unit cost of technical operation [12]. Two strategies are selected to maintain the vehicle in good technical condition: maintenance and repair. By comparing the unit maintenance cost by operating time $C_{I-I}$ with the unit repair $C_{I I}$ cost, you can determine the minimum maintenance frequency.

The initial data are the one-time costs of repair $c$ and maintenance $d$, the probability distribution density of the random $f(x)$ variable of the time to failure of the array with dimension $N$ (Figure 1). 


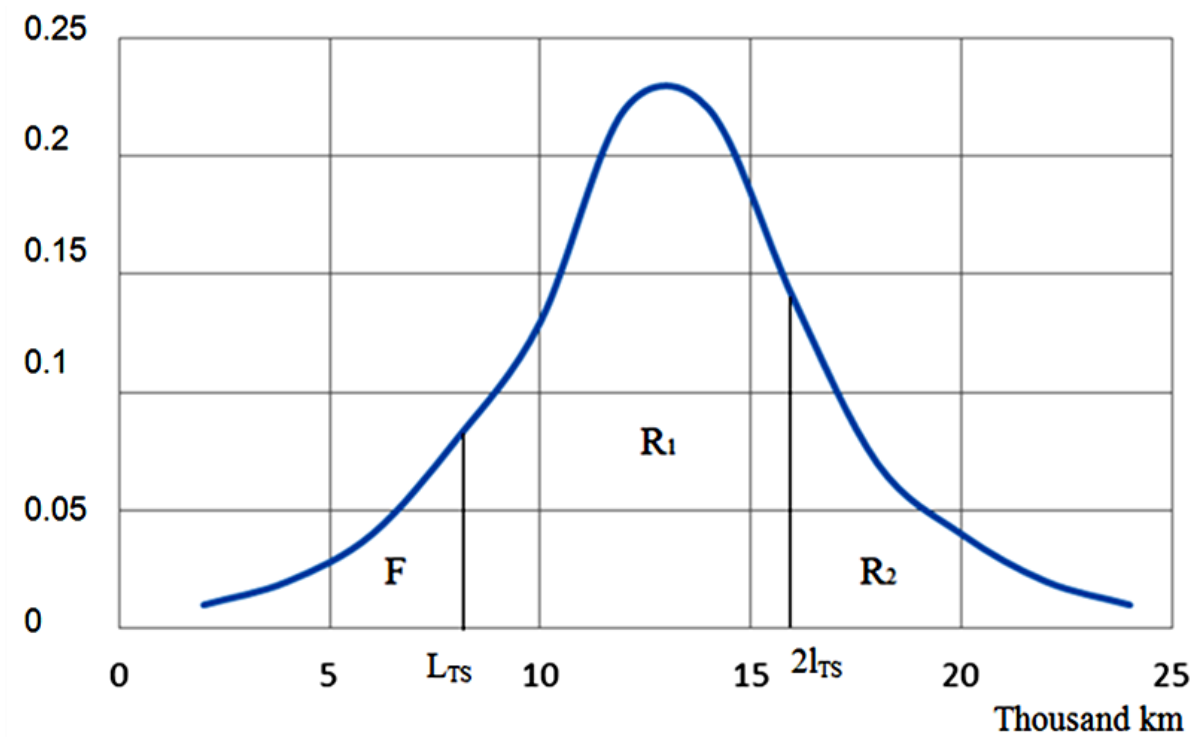

Fig. 1. Failure probability distribution

We determine the average value of the time to failure:

$$
\bar{x}=\sum_{1}^{m} x_{i} \cdot \omega_{i},
$$

where

$$
\omega_{i}=\frac{n_{i}}{N}
$$

is the probability of failure in the interval $i$.

Unit cost of repair $(P) C_{I I}$ (repair on demand)

$$
C_{I I}=\frac{c}{\bar{x}}
$$

When assigning the frequency of technical service (TS) $x=l_{T S}$, a failure occurs for the values $x \leq l_{T S}$, and they require restoration of operability - routine repairs.

We determine the average operating time before current repair for failed products using the formula:

$$
l_{p}=\frac{\sum^{l_{p}} x_{i} \cdot \omega_{i}}{\sum^{l_{p}} \omega_{i}} .
$$

For the values $x \geq l_{T S}$, a maintenance operation must be performed.

We determine the unit costs for the $\mathrm{C}_{\mathrm{I}}$ strategy according to the operating time:

$$
C_{I-I}=\frac{c F+d R}{l_{r} F+l_{T S} R},
$$

where $c F+d R$ - weighted average cost of performing maintenance and repair operations;

$l_{r} F+l_{T S} R$ - weighted average operating time maintenance and repair operations;

$l_{T S}$ - frequency of maintenance when performed by operating time;

$l_{r}$ - average operating time of elements $\left(x_{i}<l_{\mathrm{TS}}\right)$ that failed with probability $\mathrm{F}$;

$R=R_{1}+R_{2}$ - probability of uptime for $x \geq l_{T S}$.

The method allows to take into account both the technical component and the economic components of the issue. However, for products $2 l_{T S} \leq x_{i}$, there is an unnecessary need for technical service. 
Therefore, it is proposed to determine the frequency of technical service by comparing the specific costs of repair and maintenance according to their condition $[13 ; 14]$. To do this, we divide the maintenance operations into the diagnostic part and the executive part. The executive part occurs only based on the results of the diagnostic part. Accordingly, the cost of the maintenance operation is also broken down.

$$
d=d_{k}+d_{u},
$$

where $d_{k}-$ cost of the diagnostic part of the maintenance operations; $d_{k}$ - cost of the executive part of the technical service operations.

Then the unit cost of maintenance and repair as of $C_{I-I I}$ :

$$
C_{I-I I}=\frac{c F+R_{1}\left(d_{k}+d_{u}\right)+R_{2} d_{k}}{l_{r} F+l_{T S} R_{1}+2 l_{T S} R_{2}},
$$

where $R_{1}=P\left\{l_{T S}<x_{i}<2 l_{T S}\right\}-$ probability of uptime for $l_{T S}<x_{i}<2 l_{T S}$.

The use of this method allows to choose the frequency of maintenance of motor vehicles at the minimum unit cost of maintenance and repair [15].

\section{Discussion of the results}

We will conduct a comparative analysis of the proposed methods. There is a data array of random values of the time to failure dimension $N=100$. Choose the cost of operations $P c=10$ dollar, for operations TS: $d_{k}=1.5$ unit and $d_{u}=1.5$ unit. The calculated values of the random variable characteristics are shown in Table 1.

\section{Calculated values of the random variable characteristics}

Table 1

\begin{tabular}{|c|c|c|c|c|c|c|}
\hline Interval & Interval, & Midpoint of the & Number of & Frequency & \multicolumn{2}{|c|}{ Estimating probabilities } \\
\cline { 5 - 7 } number & thousand km & interval & refusals & $\boldsymbol{\omega}_{\boldsymbol{i}}$ & Refusal $\boldsymbol{F}$ & Reliability $\boldsymbol{R}$ \\
\hline 1 & $1-3$ & 2 & 1 & 0.01 & 0.01 & 0.99 \\
\hline 2 & $3-5$ & 4 & 2 & 0.02 & 0.03 & 0.97 \\
\hline 3 & $5-7$ & 6 & 4 & 0.04 & 0.07 & 0.93 \\
\hline 4 & $7-9$ & 8 & 8 & 0.08 & 0.15 & 0.85 \\
\hline 5 & $9-11$ & 10 & 13 & 0.13 & 0.28 & 0.72 \\
\hline 6 & $11-13$ & 12 & 22 & 0.22 & 0.5 & 0.5 \\
\hline 7 & $13-15$ & 14 & 22 & 0.22 & 0.72 & 0.28 \\
\hline 8 & $15-17$ & 16 & 14 & 0.14 & 0.86 & 0.14 \\
\hline 9 & $17-19$ & 18 & 7 & 0.07 & 0.93 & 0.07 \\
\hline 10 & $19-21$ & 20 & 4 & 0.04 & 0.97 & 0.03 \\
\hline 11 & $21-23$ & 22 & 2 & 0.02 & 0.99 & 0.01 \\
\hline 12 & $23-25$ & 24 & 1 & 0.01 & 1 & 0 \\
\hline
\end{tabular}

Average value of a random variable:

$$
\bar{x}=\sum_{i} x_{i} w_{i}=12.98 \text { thousand } \mathrm{km} .
$$

Mean square deviation:

$$
\sigma=\sqrt{\frac{\sum_{i=1}^{n}\left(x_{i}-\bar{x}\right)^{2} w_{i}}{n-1}}=1.21 \text { thousand } \mathrm{km} .
$$

Coefficient of variation:

$$
\vartheta=\frac{\sigma}{x}=\frac{1.21}{12.98}=0.093 .
$$


We determine the unit cost of maintenance and repair by the operating time and summarize the data in Table 2.

Table 2

\section{Determined cost of maintenance and repair}

\begin{tabular}{|c|c|c|c|c|c|c|c|c|}
\hline $\begin{array}{l}\text { Interval } \\
\text { number }\end{array}$ & $\begin{array}{c}\text { Interval } \\
\Delta x_{i}, \\
\text { thousand } \\
\text { km }\end{array}$ & $\begin{array}{l}\text { Midpoint of } \\
\text { the interval } \\
\quad x_{i}, \\
\text { thousand km }\end{array}$ & $\begin{array}{c}\text { Frequency } \\
w_{i}=p_{i}\end{array}$ & $F$ & $R$ & $\begin{array}{c}\text { Frequency of } \\
\text { maintenance } \\
\qquad l_{T S}, \\
\text { thousand } \mathrm{km}\end{array}$ & $\begin{array}{c}\text { Frequency of } \\
\text { repair } \\
l_{r}, \\
\text { thousand km }\end{array}$ & $\begin{array}{c}\text { Unit costs } \\
C_{I-I}, \\
\text { units per } \\
\text { thousand km }\end{array}$ \\
\hline 1 & $1-3$ & 2 & 0.01 & 0.01 & 0.99 & 1 & 0 & 3.10 \\
\hline 2 & $3-5$ & 4 & 0.02 & 0.03 & 0.97 & 3 & 1 & 1.09 \\
\hline 3 & $5-7$ & 6 & 0.04 & 0.07 & 0.93 & 5 & 1.67 & 0.73 \\
\hline 4 & $7-9$ & 8 & 0.08 & 0.15 & 0.85 & 7 & 2.43 & 0.64 \\
\hline 5 & $9-11$ & 10 & 0.13 & 0.28 & 0.72 & 9 & 3.63 & 0.66 \\
\hline 6 & $11-13$ & 12 & 0.22 & 0.5 & 0.5 & 11 & 4.65 & 0.83 \\
\hline 7 & $13-15$ & 14 & 0.22 & 0.72 & 0.28 & 13 & 6.93 & 0.93 \\
\hline 8 & $15-17$ & 16 & 0.14 & 0.86 & 0.14 & 15 & 9.41 & 0.88 \\
\hline 9 & $17-19$ & 18 & 0.07 & 0.93 & 0.07 & 17 & 11.13 & 0.82 \\
\hline 10 & $19-21$ & 20 & 0.04 & 0.97 & 0.03 & 19 & 11,98 & 0.80 \\
\hline 11 & $21-23$ & 22 & 0.02 & 0.99 & 0.01 & 21 & 12.55 & 0.79 \\
\hline 12 & $23-25$ & 24 & 0.01 & 1 & 0 & 23 & 12.87 & 0.78 \\
\hline
\end{tabular}

Unit costs are:

$$
\mathrm{C}_{\mathrm{II}}=\frac{10}{12.98}=0.78 \text { units per thousand } \mathrm{km} \text {. }
$$

When choosing $l_{T S}=9$ a thousand $\mathrm{km}$, unit costs will decrease by, unit costs will decrease by

$$
\mathrm{C}_{\mathrm{II}} / \mathrm{C}_{\mathrm{I}-\mathrm{I}}=0.78 / 0.64=1.2 \text { times. }
$$

Let us determine the frequency of maintenance by comparing the unit costs of repairs with the unit costs of repairs and maintenance according to the technical condition. The calculated values are shown in Table 3.

Determined frequency of maintenance

Table 3

\begin{tabular}{|c|c|c|c|c|c|c|c|c|}
\hline $\begin{array}{c}\text { Frequency of } \\
\text { TS } \boldsymbol{l}_{\boldsymbol{T S}}, \\
\text { thousand km }\end{array}$ & $\begin{array}{c}\text { Repair } \\
\text { frequency } \\
\text { thousand km }\end{array}$ & $\boldsymbol{F}$ & $\boldsymbol{R}_{1}$ & $\boldsymbol{R}_{2}$ & $\boldsymbol{c} \boldsymbol{F}$ & $\boldsymbol{d}_{\boldsymbol{k}} \boldsymbol{R}$ & $\boldsymbol{d} \boldsymbol{R}_{2}$ & $\begin{array}{c}\text { Unit costs } \\
\boldsymbol{C}_{\boldsymbol{I}-I I}, \text { units per } \\
\text { thousand km }\end{array}$ \\
\hline 1 & 0.00 & 0.01 & 0 & 0.99 & 0.1 & 0 & 2.97 & 1.55 \\
\hline 3 & 1.00 & 0.03 & 0.04 & 0.93 & 0.3 & 0.060 & 2.79 & 0.55 \\
\hline 5 & 1.67 & 0.07 & 0.23 & 0.70 & 0.7 & 0.345 & 2.10 & 0.39 \\
\hline 7 & 2.43 & 0.15 & 0.57 & 0.28 & 1.5 & 0.855 & 0.84 & 0.38 \\
\hline 9 & 3.63 & 0.28 & 0.65 & 0.07 & 2.8 & 0.975 & 0.21 & 0.49 \\
\hline 11 & 4.65 & 0.50 & 0.49 & 0.01 & 5.0 & 0.735 & 0.03 & 0.73 \\
\hline 13 & 6.93 & 0.72 & 0.28 & 0 & 7.2 & 0.420 & 0 & 0.88 \\
\hline 15 & 9.41 & 0.86 & 0.14 & 0 & 8.6 & 0.210 & 0 & 0.86 \\
\hline 17 & 11.13 & 0.93 & 0.07 & 0 & 9.3 & 0.105 & 0 & 0.81 \\
\hline 19 & 11.98 & 0.97 & 0.03 & 0 & 9.7 & 0.045 & 0 & 0.80 \\
\hline 21 & 12.55 & 0.99 & 0.01 & 0 & 9.9 & $0 ., 015$ & 0 & 0.78 \\
\hline 23 & 12.87 & 1 & 0 & 0 & 10 & 0 & 0 & 0.78 \\
\hline 25 & 13.11 & 1 & 0 & 0 & 10 & 0 & 0 & - \\
\hline
\end{tabular}


The frequency of maintenance, when determined by the proposed method, is $l_{T S}=7$ thousand $\mathrm{km}$. At the same time, the unit costs are reduced compared to a simple restoration of the working capacity $C_{I I} / C_{I-I I}=0.78 / 0.38=2.1$ times, and compared to the operating time $C_{I I} / C_{I-I I}=0.64 / 0.38=1.68$.

\section{Conclusions}

The proposed method for determining the frequency of maintenance of motor vehicles allows to take into account objective and subjective factors that affect the technical condition of the equipment, as well as to reduce the specific cost of technical operation. The frequency of maintenance, when determined by the proposed method, is $l_{T S}=7$ thousand $\mathrm{km}$. At the same time, the unit costs are reduced in comparison with a simple restoration of the working capacity $C_{I I} / C_{I-I I}=0.78 / 0.38=2.1$ times, and compared to the operating time $C_{I I} / C_{I-I I}=0.64 / 0.38=1.68$. The result obtained depends quite strongly on the ratio of repair $c$ and maintenance costs $d$. This adjustment can be made by engineering and technical personnel based on the results of operational observations of the time to failure.

\section{References}

[1] Caban J., Droździel P., Krzywonos L., Rybicka I., Šarkan B., Vrábel J. Statistical Analyses of Selected Maintenance Parameters of Vehicles of Road Transport Companies// Volume 13, Issue 1, March 2019, pp. 1-13.

[2] Muradyan L. A., Shaposhnik V. Yu., Mishchenko A. A. Methodological bases for determining the operational characteristics of non-self-propelled rolling stock // Science and progress of transport. Bulletin of Dnepropetrovsk National University of railway transport, Dnepropetrovsk 2016, No. 1 (61) ISSN 2307-3489 (Print).

[3] Goncharenko A. Optimizing maintenance frequency with subjective preference distributions // Vìsnik Nacìonal'Nogo Avìacìjnogo Unìversitetu (2017-07-01) Vol. 71, pp. 51-56,

[4] Chen Y.H., Chou Y.L., Tsai C.L., Chang H.C. Evaluating car centre service quality with modified Kano model based on the first-time buyer's age, Cogent Business \& Management, 5:1, 1441593 p.

[5] Gunay B. An overview of longitudinal characteristics of road traffic flow //Journal of Engineering Sciences 20028 (2) Y11 2002, Cilt 8, Say1 2, Sayfalar pp. 247-254.

[6] Kuznetsova E. S., Technical operation of vehicles. Ed. -M.: Transport, 1991. 416 p.

[7] Malkin, V. S., Yu. S. Bugakov. Fundamentals of operation and repair of cars. Rostov: 2007. 431 p.

[8] Makarova A. N. The method of operational adjustment of the standards of frequency of maintenance, taking into account the actual operating conditions of cars. Diss. author diss. Candidate of technical Sciences 2015 Tyumen, $16 \mathrm{p}$.

[9] Khaliullin F. Kh., Galiev I. G. Accounting for the operating conditions of motor vehicles in determining the standards of technical operation // Bulletin of the Kazan State Agrarian University. Kazan: 2011.- № 2 (20). Pp. 106-108.

[10] Chekmarev A. N., Zibarev A. G., Ryzhkov A. I. Methodical bases of maintenance of operational reliability of the car./Problems of mechanical engineering and automation. - Moscow. 1998, no. 12, pp. 20-25.

[11] Kichigin S. Yu., Elesin S. V. Analysis of the goals of technological transport departments for maintenance and repair of cars and special equipment // Transport Systems of Siberia: Materials of the II All-Russian Scientific and Technical Conference. conf. - Krasnoyarsk: KSTU, 2004. 101-102 p.

[12] Khaliullin F.K., Matyashin A.V., Akhmetzyanov R.R, Medvedev V.M., Lushnov M.A. Prospects for using the Bayes algorithm for assessing the technical condition of internal combustion engines // IOP Conference Series: Materials Science and Engineering, Volume 635, 10th International Conference on Mechatronics and Manufacturing (ICMM 2019) 21-23 January 2019, Bangkok, Thailand, DOI: 10.1088/1757-899X/635/1/012016

[13] Khaliullin F.K., Aladashvili J.K., Nurmiev A.A., Pikmullin G.V., Sinitsky S.A. Determination of statistical data of conditional probabilities of the technical condition of internal combustion engines when compiling the Bayes diagnostic table// IOP Conference Series: Materials Science and Engineering, Volume 635, 10th International Conference on Mechatronics and Manufacturing (ICMM 2019) 21-23 January 2019, Bangkok, Thailand, DOI:10.1088/1757-899X/635/1/012017 
[14] Nuriev L.M., Yakhin S.M., Aliakberov I.I., Galiev I.G., Sinitsky S.S. Kinematics and parameters for spiral-helical machinery unit used for secondary tillage // International Conference on Technological Solutions and Instrumentation for Agribusiness: Earth and Environmental Science Volume 488, Issue 1, Stavropol; Russian Federation, 2020.

[15] Robert Bosch GmbH, Foerstner Dirk, Weber Reinhard. Fehlerdiagnosever-fahren und vorrichtung: DE-Aktenzeichen 10326557. B* 60 R 16/02. Anmeldedatum 12.06.2003, Veroffentlichungstag im Patentblatt 05.01.2005. 